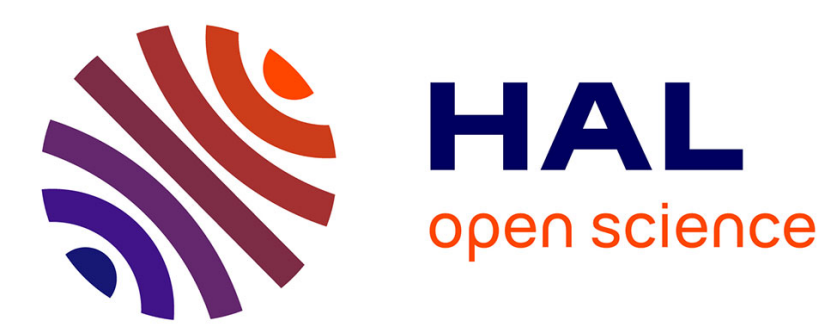

\title{
City Size distributions and metropolisation
}

Denise Pumain, François Moriconi-Ebrard

\section{- To cite this version:}

Denise Pumain, François Moriconi-Ebrard. City Size distributions and metropolisation. GeoJournal, 1997, 43 (4), pp.307-314. hal-01524120

\section{HAL Id: hal-01524120 \\ https://hal.science/hal-01524120}

Submitted on 17 May 2017

HAL is a multi-disciplinary open access archive for the deposit and dissemination of scientific research documents, whether they are published or not. The documents may come from teaching and research institutions in France or abroad, or from public or private research centers.
L'archive ouverte pluridisciplinaire HAL, est destinée au dépôt et à la diffusion de documents scientifiques de niveau recherche, publiés ou non, émanant des établissements d'enseignement et de recherche français ou étrangers, des laboratoires publics ou privés. 


\title{
City size distributions and metropolisation
}

\author{
Pumain, Denise; Université Paris I, CNRS, URA 1243, 13 rue du Four, \\ 75006 Paris, France (e-mail: pumain@paris.msh-paris.fr) \\ Moriconi-Ebrard, François; CEDEJ, P.O. Box 494, Dokki, Cairo, \\ Egypt
}

Received 20 March 1997; accepted 1 October 1997

\begin{abstract}
Many controversial questions about the shape and evolution of city size distributions can be solved if reliable, large and comparable set of data are used for several countries. We provide new empirical evidence by using the large data base 'Geopolis', which has strictly comparable figures for all towns and cities of the world over 10,000 inhabitants between 1950 and 1990. A Pareto model is used for identifying as metropolises one or a few large cities for each national urban system. From those data, two empirical power laws are established, linking the size of the metropolises to the size of their national urban system. The first is a transversal law: for a set of countries at a given date, the share of population concentrated in metropolises tends to decrease when larger countries are considered. The second law, which is longitudinal, shows that metropolises in the past have grown in a systematic way more rapidly than the rest of their urban system, invalidating Gibrat's urban growth model. Such empirical regularities could help for predicting the future of nowadays observed metropolisation trends.
\end{abstract}

Key words: urban system, city size distribution, metropolis

\section{Introduction}

A growing concern for urban problems, especially in large cities, and their comparison all over the world, is emerging, as shown by the Habitat conference hold in Istanbul by the United Nations in 1996, or by recurrent anxious questions in newspapers about the future of mega-cities and their sustainability. Paradoxically, to answer simple questions as: where are located the largest cities in the world? Is that city too large? Will this metropolis grow further? Is there any limit to the size of a city? . . . three difficult prerequisites are necessary: first, relevant and comparable data base for measuring city size; second, knowledge about the system of cities including the city under consideration; and third, reliable models of the structure and dynamics of urban systems for comparison and prediction. The coherence in the relative size and evolution of ci- ties belonging to the same territory is a fact which has been recognised a long time ago by geographers.

A vast literature has been written about the question of the shape of city size distributions in urban systems (for reviews see Robson, 1973, Sheppard, 1982, Pumain, 1982). Usually the cities belonging to the same region or to the same country are strongly differentiated according to their size. There is strong evidence regarding a kind of invariance in the statistical distribution of city sizes. The size distribution is highly skewed, with many small towns located close to each other, fewer and more distant medium-sized cities and only a few very large cities which are located on average far from each other. The number of cities is roughly in an inverse geometrical progression to their size. Such types of city size distributions can be found everywhere in the world (Zipf, 1949; Rosen and Resnick, 1980; Parr, 1985; Moriconi-Ebrard, 1993). They seem 
to have maintained the same shape for a very long time (deVries, 1984; Fletcher, 1986).

This distribution was formalized a long time ago (Auerbach, 1913). It is usually known as the 'rank-size rule' as described by Zipf (1949): the logarithm of the population size of a city is a linear function of the logarithm of its rank in the urban hierarchy. The cumulative frequency distribution of the sizes of cities is also similar to a Pareto function (Simon, 1955) or to a lognormal distribution (Gibrat, 1931). The slope of the Pareto distribution, or the dispersion of the lognormal function, are indicators of the degree of concentration of urban populations (in other words, they are measures of the inequalities in size among cities).

It is not obvious from existing observations which statistical model is closer to empirical data. According to various studies, reasonable adjustments can be obtained either with Zipf's (1949) simple 'rank size rule' model, (a Pareto distribution with one parameter), or by using a Pareto model with three parameters (Barbut, 1988), or a lognormal distribution with three parameters (Gibrat, 1931; Robson, 1973; Pumain, 1982), or other variations on dissymetrical distributions (Malecki, 1980; Guérin-Pace, 1993). After comparing a large number of statistical models, Quandt's conclusion was that the best statistical fit could not be chosen as a valuable criterion for identifying the nature of city size distribution, and that theoretical considerations had to be included in the decision (Quandt, 1964).

The highly skewed distribution, which is a characteristic feature of all observed urban systems, however has no unambiguous correspondence in any theoretical explanation. The shape of the distribution is by itself not a sufficient description for deducing satisfying explanations. Indeed, it can be related to a large variety of explanatory processes. It is in that sense that B. Robson (1973) described Zipf's 'rank-size rule' or Pareto distribution as an 'over-identified model'. One has then to proceed the other way round: after choosing a reasonable theory for the explanation of the existence of an urban hierarchy, it has to be tested if the corresponding theoretical distribution of city size is of a type compatible with one or several of the statistical models used for describing that distribution.

The most useful theoretical explanations which link the city size distribution to urban theory are of two kinds. The first, central place theory, though a static and partial theory of urban systems in its geometrical (Christaller, 1933) or mathematical (Beckman, McPherson, 1970) form, does provide economic and territorial rationales for the existence of an urban hierarchy. When those principles and the evolutionary properties of urban systems are integrated into dynamic models, it becomes possible to simulate the emergence of an urban hierarchy from the interac- tions between settlements (Allen and Sanglier, 1979; Bura et al., 1996). The second kind of explanatory model, which we have chosen here to use as a reference, is a simpler stochastic model of urban growth which deduces the distribution of city size from a rather plausible hypothesis about the distribution of cities growth rates in an urban system (Gibrat, 1931; Robson, 1973; Pumain, 1982; Guérin-Pace, 1993).

Whatever theoretical model is chosen, the corresponding statistical distribution of city sizes has to be tested on reliable empirical data. Due to the lack of comparativeness of most readily available urban statistics, several conjectures which have been made about city size distribution have never been properly tested. Debatable affirmations can still be found, even in recent publications, because such studies use too narrow samples of cities or ill-defined urban populations (for instance, Rosen and Resnick (1980) or Alperovitch, (1993)). In this paper we shall use a large data base, GEOPOLIS, including comparable population figures for more than 25,000 urban areas in the world, (Moriconi-Ebrard, 1994). Using first the simple Pareto model, which may not be the best one from a theoretical point of view, but which has the advantage of convenience for comparisons, we discuss a few controversial questions about city size distributions, as well as the distribution of city size inequalities or primacy levels among the countries of the world. We emphasize the need for a theory that includes the notion of metropolis and refers to the territorial structure in which the urban networks are embedded. Second, using Gibrat's model of urban growth as a reference, we try to throw some light on the now fashionable concept of metropolisation.

\section{The GEOPOLIS data base}

GEOPOLIS is a data base that includes strictly comparable population figures for all towns and cities in the world having 10,000 inhabitants or more. It has been developed and maintained by F. MoriconiEbrard (1994). Population figures have been collected from the national censuses for local units (municipalities, or smaller subdivisions when needed) and aggregated according to the spatial continuity of the builtup area. The data base then uses the concept of the urban agglomeration, as defined by United Nations's recommendations (1978). The limits of towns and cities have been adjusted to the administrative boundaries of local units and then maintained constant over time in order to avoid the jumps in population figures attributable to the spatial extension of agglomerations. For each of the 26,000 towns and cities of the data base, population is given (or estimated after the 


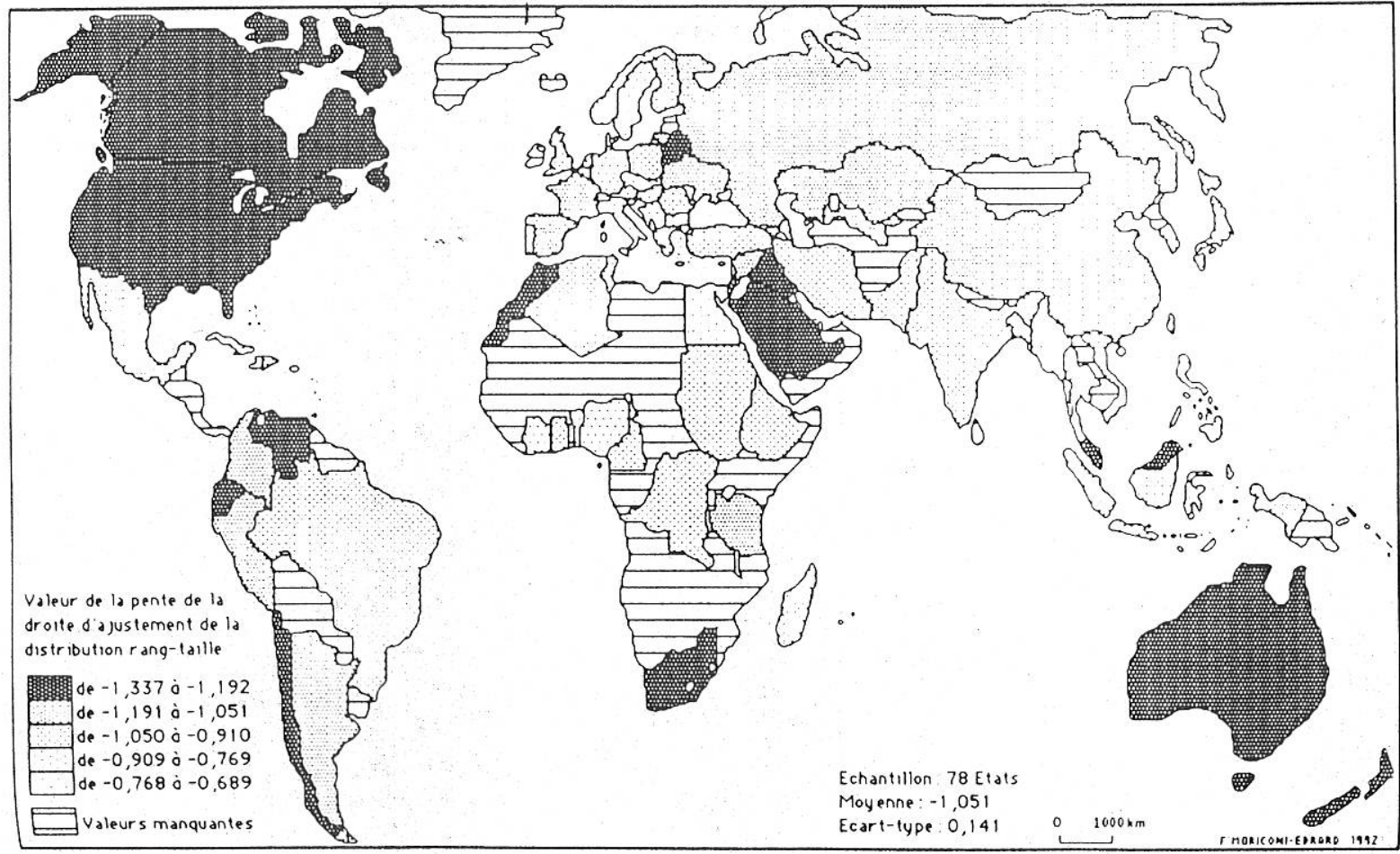

Figure 1. Degree of inequality in city sizes. Values of the exponent $a$ of the adjusted Pareto distribution.

nearest census in time) for 1950, 1960,1970, 1980 and 1990, according to the spatial delimitation of 1990.

\section{Inequalities in city size are related to the age of settlement systems}

As it has been widely used in previous international comparisons, we will use the slope of Zipf's rank-size rule (the inverse of the parameter of a Pareto law) as an indicator of the degree of inequality in city sizes distributions. For each national system of cities (including at least 30 towns and cities), this parameter $a$ has been estimated after equation (1):

$$
\log \mathrm{P}=\mathrm{K}-a \log \mathrm{R}
$$

where $\mathrm{P}$ is the population of a city belonging to the system and $\mathrm{R}$ its rank in the urban hierarchy, by decreasing order of population size, and $\mathrm{K}$ is a constant.

It must be recalled (after Parr, 1985; Malecki, 1980 and others) that the estimation of the parameter $a$ is very sensitive to sample sizes. Rosen and Resnick (1980), whose results are taken for granted by Alperovich (1993), have compared 44 countries by considering only their first 50 cities or all cities with 100,000 inhabitants or more (these data are regularly published in UNO Demographic Statistics). Their estimations are very different from ours: they found, for instance, an exponent of 1.963 for Australia and 1.537 for Nigeria, whereas we found 1.369 and 0.843 respective- ly. We also found values which are different from those measured by Parr (1985) who calculated for Egypt 0.998 in 1947 and 0.947 in 1970, whereas we have 0.865 for 1950 and 0.753 for 1970 respectively.

Figure 1 describes the distribution of the city sizes inequality index $a$ for 78 countries; those values are averaged for large regions of the world and by type of countries in Table 1.

Contrary to a frequent hypothesis, the global level of inequalities in city sizes, as reflected by the values of parameter $a$, are not correlated with the level of economic development. The same average is found for industrialised and developing countries, approximately 1.05. Despite rather large intra-group variations, a significant difference can be found between 'old' and 'recent' urban systems: the former including those mainly in Europe and Asia, the latter in America and Australia.

To illustrate that finding, we represent the rank-size distributions for North America and the European Union (Figure 2). Whereas the urban population of North America in only inferior by $40 \%$ to the European one, the new continent has only one-third as many cities as the old one. The 30 largest North-American cities are all much larger than their European counterparts, whereas Europe has a much greater number of small and medium-size towns and cities. This, when related to average spacings between cities $(13 \mathrm{~km}$ in Europe against $48 \mathrm{~km}$ in USA), can be explained by differences in the age of the settlement systems. Spacings between towns and cities have been determined 
Table 1. Index of inequality of city sizes according to world regions and levels of development

\begin{tabular}{|c|c|c|c|c|}
\hline Zone & 1950 & 1960 & 1970 & 1980 \\
\hline \multicolumn{5}{|l|}{ Developed countries } \\
\hline Western Europe & 0.99 & 1.00 & 1.01 & 1.00 \\
\hline North America & 1.23 & 1.25 & 1.27 & 1.26 \\
\hline Pacific Asia & 0.81 & 0.87 & 0.94 & 1.02 \\
\hline Australia \& New Zealand & 1.52 & 1.38 & 1.29 & 1.26 \\
\hline Ex-Comecon & 0.92 & 0.98 & 1.02 & 1.05 \\
\hline \multicolumn{5}{|l|}{ Developing countries } \\
\hline Africa South of Sahara & 1.15 & 1.03 & 1.02 & 0.98 \\
\hline Latin America & 1.09 & 1.09 & 1.13 & 1.15 \\
\hline Middle East \& North Africa & 1.01 & 1.02 & 1.10 & 1.12 \\
\hline South Asia & 0.97 & 0.96 & 0.98 & 0.99 \\
\hline China & & & & 1.07 \\
\hline Developed countries & 0.99 & 1.01 & 1.04 & 1.05 \\
\hline Developing countries & 1.04 & 1.02 & 1.05 & 1.05 \\
\hline Ancient World & 0.97 & 0.99 & 1.02 & 1.02 \\
\hline New World & 1.15 & 1.15 & 1.18 & 1.18 \\
\hline
\end{tabular}

NB: The index value is an unweighted mean for all countries in the area indicated.Developed countries are: countries of North America, Europe, Japan, South Korea, Taïwan, Australia, New Zealand. New World: countries of North and South America and Oceania.

by the time necessary for connecting them when they have developed. This is one argument in favour of including the speed of the means of inter-urban transportation in the theoretical concept of urban systems (Mackinder, 1890; Reclus, 1895; Pumain and Robic, 1996).

During historical times, the inequality in city size has been increasing. Empirical evidence from historical data (Bairoch, Batou and Chèvre, 1988) shows a clear evolution from values inferior to or around 0.7 in many countries before the XIXth century to values significantly higher for distributions observed since the middle of XXth century, whose slopes are usually between 0.9 and more than 1 . However, the direction of recent evolution is by no means clear: between 1950 and 1990, the value of the $a$ parameter has steadily increased in 19 countries, steadily decreased in 9 others, while it followed no regular evolution in the remaining 21 others. There is a rather general trend to a diminution of the contrast in the more developed countries, but there are exceptions (USA, France, Japan, Russia, Hungary or Greece). The diversity in evolutionary paths is still larger in third-world countries.

Over time, there is no indication either of any convergence toward more or less regularity in the shape of the size curve. This contradicts an hypothesis made, for instance, by Berry (1964) and repeated many times since. On the contrary, the persistence of systematic deviations from the Pareto model seems to be the rule, especially in the upper part of the city size distribution.

\section{A statistical definition of metropolis}

The observed distributions of city size rarely fit the statistical models exactly. A few examples of regular distributions can be found, as for instance for the United States (Figure 3). In a limited number of cases, as for India, the curve is concave to the origin, but in most cases it is convex and exhibits a more or less pronounced discontinuity between one (in the case of France) or two or three (as in Italy) or even five (as in

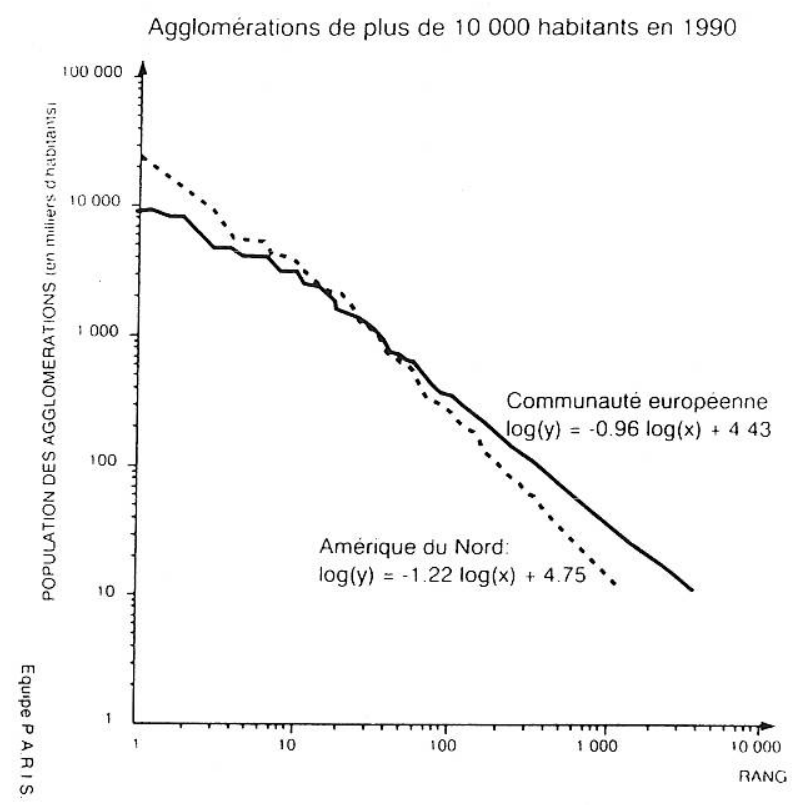

Figure 2. Rank size distributions for European and North American cities.

Source: Moriconi-Ebrard, 1993. 


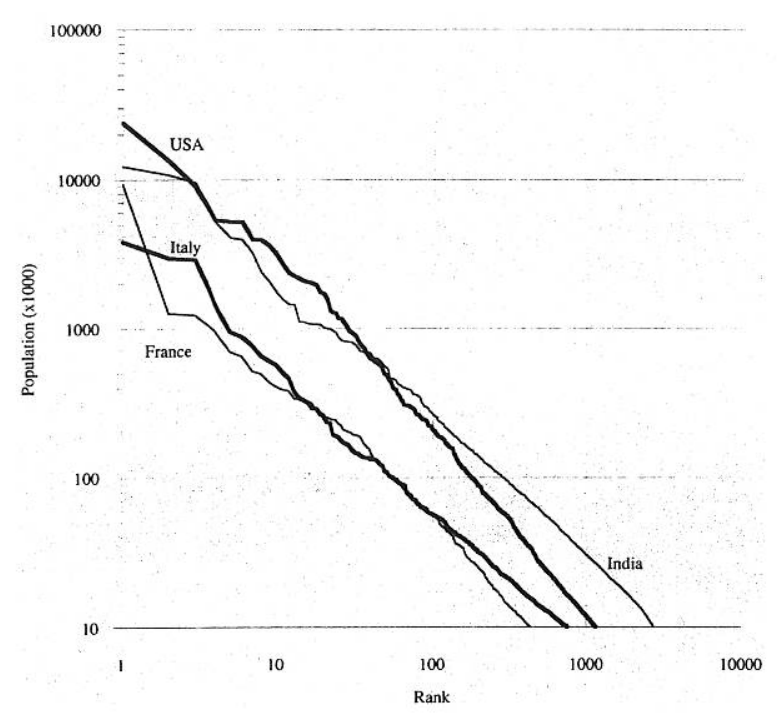

Figure 3. Rank-size distribution in 4 countries.

Australia) cities which are very large, and the rest of the urban system.

\subsection{Identifying metropolises}

The main deviations from the statistical reference provided by the Pareto distribution are usually observed in the upper levels of urban hierarchies. Jefferson (1939) called 'the law of primacy' the fact that the size of the first city is usually much larger than one would expect from the size of the other towns and cities in the national distribution of city sizes. He computed a 'primacy index' as the ratio between the population of the largest and second largest city and found that in most cases it was much larger than the value of two which would correspond to Zipf's rank size rule (for a Pareto distribution with a parameter $a$ value of 1.3 , the expected ratio would be 2.5).

We have computed this primacy index for each state based on the data from the GEOPOLIS data base. The mean value, 5.2 for all countries of the world, neatly confirms Jefferson's hypothesis of a systematic trend to primacy in urban systems. Table 2 indicates average values for various parts of the world. Despite a large heterogeneity within the subsets, it may be concluded that there is a significant difference between developing countries, with a mean value of 6.0 , and developed countries, with a primacy index of only 3.5. This may be referred to as the well-known duality in the degree of openness to the world economy in developing countries.

Several authors noticed that in many urban systems not only one city but two or more could develop population sizes much larger than would be predicted given the rest of the urban system. Various indexes have been suggested for measuring this, by considering ratios between populations of the first and of five largest cities, or comparing the first three to the ten largest. . We have computed a 'macrocephaly index' by identifying the largest discontinuity in the distribution of city sizes (i.e. the highest value of the ratio of populations of any successively ranking cities) and measuring the ratio between the population size of the corresponding cities. Table 2 gives statistics about this macrocephaly index, and confirms the global conclusions derived from primacy index. The concept of macrocephaly, however, can also be helpful in identifying countries where several metropolises are found at the head of an urban system. The main discontinuity between cities of successive ranks usually appears between the first and the second (as in France of in Romania), sometimes between the second and the third (as in Spain or Brazil), in some rare cases further but never beyond the rank number eight (for Germany). This was used for defining in a non-ambiguous way which cities have been considered as 'metropolises' in the following sections: they are all those ranking above the main discontinuity in the city size distribution.

\subsection{A static 'law of metropolises'}

Using the GEOPOLIS data base, F. Moriconi-Ebrard derived a general rule which he called 'the law of metropolises'. According to this empirical regularity, it is stated that, at a given date, there is a strong relation between the total number of inhabitants $P_{\mathrm{mi}}$ inhabiting the metropolises (as defined above, it means adding the populations of one to eight cities maximum,

Table 2. Primacy and Macrocephaly indexes for 1980

\begin{tabular}{lll}
\hline Zone & $\begin{array}{l}\text { Primacy } \\
\text { index }\end{array}$ & $\begin{array}{l}\text { Macroce } \\
\text { index }\end{array}$ \\
& & \\
\hline Developed countries & 4.27 & 5.31 \\
Western Europe & 2.22 & 3.69 \\
North America & 2.52 & 2.70 \\
Pacific Asia & 1.74 & 2.71 \\
Australia \& New Zealand & 3.73 & 3.88 \\
Eastern Europe & & \\
Developing countries & 4.97 & 5.44 \\
Africa South of Sahara & 6.86 & 7.31 \\
Latin America & 5.81 & 6.18 \\
Middle-East \& North-Africa & 8.0 & 8.65 \\
South Asia & 1.33 & 1.33 \\
China & 3.48 & 3.85 \\
Developed countries & 6.02 & 6.52 \\
Developing countries & 4.98 & 5.36 \\
Ancient World & 5.89 & 6.49 \\
New World &
\end{tabular}

NB: Values are unweighted means for all countries included in an area. 


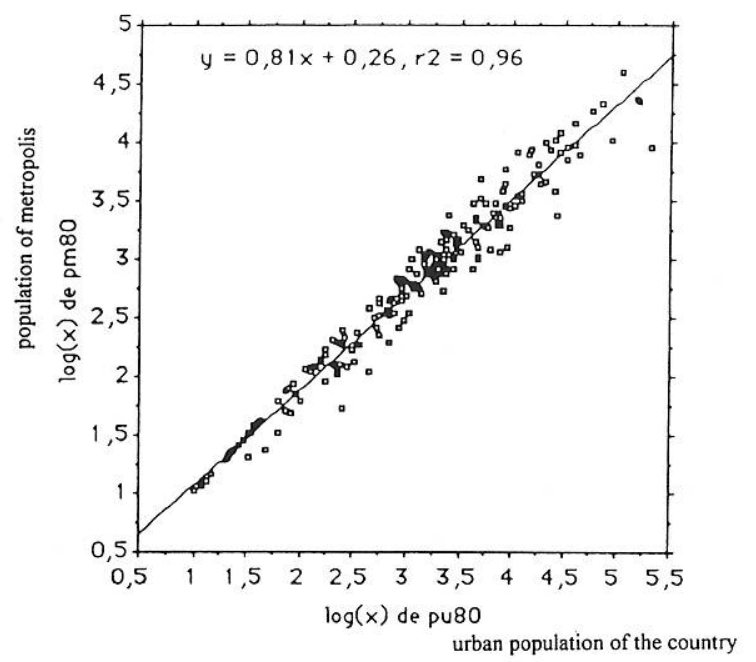

Figure 4. A transversal law of metropolises.

according to the country) and $\mathrm{P}_{\mathrm{ui}}$, the total urban population of each national country $\mathrm{i}$ :

$$
\mathrm{P}_{\mathrm{mi}}=\mathrm{P}_{\mathrm{ui}}^{b}
$$

where $b$ is a constant parameter. Adjusting this model to the distributions of population of the metropolises of 177 states by logarithmic transformation

$$
\log \mathrm{P}_{\mathrm{mi}}=b \log \mathrm{P}_{\mathrm{ui}}+\log \mathrm{k}
$$

it was found:

$$
\log \mathrm{P}_{\mathrm{mi}}=0.815 \log \mathrm{P}_{\mathrm{ui}}+0.26
$$

or:

$$
\mathrm{P}_{\mathrm{mi}} \approx 0.26 \cdot \mathrm{P}_{\mathrm{ui}}^{0.815}
$$

This power function suggests that there is a general trend for larger countries (as measured by population size) to have larger metropolises, but that this is less than proportional. Therefore, the relative share of the urban population which is concentrated in the limited number (generally one or two) of the biggest cities is less important in large countries than in smaller ones (Figure 4).

This empirical rule fits the data rather well $\left(\mathrm{R}^{2}=\right.$ 0.96). It also holds for each of the five periods of observation, from 1950 to 1990 , with about the same fixed value of 0.815 for the exponent.

This result can be interpreted as a possible consequence of the specific functions which are performed by the cities belonging to the highest hierachical level of any urban system. The metropolises usually concentrate the activities which connect a country with its outside environment, i.e. the international functions. Small countries usually devote a larger part of their activity to those external relations (for instance it is well known that the exporting and importing rates are higher, all things being equal, for smaller countries). It is therefore not surprising that their metropolitan centres concentrate a larger share of the urban population than those of large countries.

\section{A longitudinal analysis for metropolises}

A comparison can be made over time between the size of metropolises and the urban population of the countries they belong. This could help to achieve a better understanding and prediction of the future evolution of the 'metropolisation' process which has been recognised as the main trend in contemporary urbanisation. This investigation can be made by using as a reference a statistical model of growth in an urban system. The best available model of reference until now has been suggested by Gibrat (1931).

\subsection{Gibrat's model as reference}

Of particular interest are the models which derive a skewed distribution of sizes from the growth process of the population of cities. Several models of the distribution of growth among cities have been designed in order to demonstrate how they could lead to a Pareto distribution (Steindl, 1965; Simon, 1955) or to a lognormal distribution (Gibrat, 1931) of city sizes. Most of these are stochastic models. Their specifications could be different but they were all based on the same kind of main hypothesis. Gibrat demonstrates that any distribution of city sizes will become a lognormal distribution if the following growth process is observed:1) cities are growing at each small time interval in a number of inhabitants which is proportional to their size (it is equivalent saying that the growth rates of cities are independent of their sizes); 2) the distribution of growth rates among cities is independent from one time interval to another. In other words, the 'law of proportional effect' assumes that the causes of urban growth are diverse and numerous, that the effect of one of them is small when compared to the total effect of all causes, and that this global effect is multiplicative, and proportional to the size of cities.

Gibrat's model has been tested on 8,000 agglomerations for 1950, 10,000 in 1960 and 12,000 in 1970. A proper description of the urban growth process is actually given by the 'law of proportional effect'. On average, the variations in the number of inhabitants of a city are roughly proportional to its size, or, in other words, within the whole urban system, urban growth rates are randomly distributed among cities, irrespective of their size. On the other hand, the spatial distri- 
butions of the growth rates are independent from one period of time to the other. Both rules hold for most periods of the growth process in many observed urban systems.

However, observations made over longer periods for national subsets of cities have always shown systematic deviations from Gibrat's stochastic growth process: there is a tendency for the largest cities to grow faster at given periods, and there are also stages of temporal autocorrelation between successive growth rates. Empirical examples have been given by Madden (1955), Robson (1973), Pumain (1982), Guérin-Pace (1993) and Moriconi-Ebrard (1993). Gibrat's stochastic 'law of proportional effect' can be seen as a very general process which would roughly describe the evolution of many hierachical and open systems - among them systems of cities -, and which is trivial since just explaining their Paretian structure by the random distribution of a multiplicative growth process. Though, in the case of cities, the process is not entirely stochastic, and the main and more frequent deviations can be interpreted as an effect of various selection processes among cities, making some of them growing slightly faster or slower than the rest of the system, according to their size or to some other properties (Pumain, 1977).

\subsection{A dynamic definition of metropolisation}

If urban dynamics were a perfectly competitive process, it would lead only to random fluctuations and on average the growth rates of cities would be the same. But the process of urban change is not perfectly ubiquitous as one would expect from a simple theory of the diffusion of innovations in space. The hierarchical diffusion process gives an initial advantage to the largest cities. Two properties can explain the advantage of the largest cities. First, their large size increases the probability of the appearance of innovations. Second, because of their size, they have more interactions within their urban networks and can capture the innovations which come from elsewhere. This explains the systematic advantage of the largest cities for urban growth, at least at the beginning of the cycles of the diffusion of innovations. The stages during which smaller cities grow faster may be regarded as periods at the end of such a cycle (Robson, 1973). There is another advantage for large cities, which is an effect of shrinking geographical space (Janelle, 1969; Juillard, 1970). With the course of time, the speed of communications is increasing, the range of the largest cities is extended in such a way that the smaller cities are short-circuited, even for low-level functions. As interurban competition is taking place in a shrinking spatio-temporal framework, the sizes in the urban hierarchy tend to become more and more contrasted.

If this process was continuously distributed in the urban hierarchy, its effect would be to increase the inequality of city sizes, as measured for instance by an increase in the value of the slope of the adjusted Pareto distribution. However, the observed phenomena of primacy and macrocephaly can only be explained if the advantage of one or a small number of large cities persists over long periods of time. This hypothesis can be explored by using an allometric model of urban growth. According to this model, an identical average growth rate between the whole system and a city should be expressed by an exponent $b$ equal to one in equation (3):

$$
\mathrm{P}_{\mathrm{mt}}=\mathrm{P}_{\mathrm{ut}}^{b}
$$

where $\mathrm{P}_{\mathrm{mt}}$ is the population of the largest city of the urban system at date $t$ and $\mathrm{P}_{\mathrm{ut}}$ is the total population of the urban system at the same date.

When adjusting the allometric model of growth for a particular city compared to the size of the urban system, significantly different values were found for the $b$ parameter in equation (3). We found values of 1.06 for London compared to Great Britain from 800 to 1850 , and 1.26 for Paris between 1831 and 1990. For Indian cities between 1901 and 1991, the value of the allometric coefficient is 1.15 ; this value remains about the same if only one or several metropolises are considered, according to the rearrangements of the top of urban hierarchy during the last century in this country. Further tests are to be made on long term series of urban statistics, in order to confirm if this should be considered as a second 'law of metropolises'.

\section{Conclusion}

We do not pretend that a simple consideration of city size and of the statistical distribution of sizes in an urban system is sufficient to identify the concept of a metropolis. Other criteria, and among them obviously functional ones, should be considered for a comprehensive definition of what is a metropolis. What we attempted to show is that in many urban systems, one or a few 'primate cities' have a significantly prominent position in terms of size, and that their size is related by rather invariant laws to the size of the urban population of the territory where they are located and to its evolution. Besides this territorial logic, which relates the size of a metropolis to the size of the country to which it belongs, there is a distinct logic in the evolution of urban systems which produces over time one (or a few) dominant metropolis(es) at the head of al- 
most every urban system. There are two empirical laws, the first is transversal whereas the second is a longitudinal one. They are derived from systematic deviations between the usual models of reference for the shape of city size distribution (Pareto law) as well as for the process of urban growth (Gibrat's model). The 'laws' could be expressed otherwise if other models of reference could be used. Further developments in the theory of the dynamics of urban systems should consider how to integrate both empirical regularities and derive more significant models, which would not consider city size only but connect it with the territorial system where they are located.

\section{References}

Allen, P.; Sanglier, M.: Dynamic models of urban growth. Journal of Social and Biological Structures 2, 269-278 (1979).

Alperovich, G.: An explanatory model of city-size distribution: Evidence from cross-country data. Urban Studies 9, 1591-1601 (1993).

Ascher, F.: Metropolis. Paris, Odile Jacob, 1995.

Auerbach, F.: Das Gesetz der Bevölkerungskonzentration. Petermans Mitteilungen 59(1), 74-76 (1913).

Bairoch, P.; Batou, J.; Chèvre, P.; La population des villes européennes de 800 à 1850 . Genève, Droz, Centre d'histoire économique internationale, 1988.

Barbut M.: Des bons et des moins bons usages des distributions paretiennes en analyse des données. Histoire et Mesure 3(1), 111128, (1988)

Beckmann, M.; McPherson, M.J.: City size distribution in a central place hierarchy: an alternative approach. Journal of Regional Science 10(1), 25-33 (1970).

Berry, B.J.L.; Garrison, W.L.: Alternate explanations of urban rank-size relationships. Annals of the Association of American Geographers 1, 83-91 (1958).

Berry, B.J.L.: Cities as systems within systems of cities, Papers of the Regional Science Association 13, 147-163 (1964).

Bura, S.; Guérin-Pace, F.; Mathian, H.; Pumain, D.; Sanders, L.: Multi-agent systems and the dynamics of settlement systems. Geographical Analysis 2, 161-178 (1996).

Chapman, G.P.: The application of information theory to the analysis of population distribution in space, Economic Geography 2, 317-333 (1970).

Christaller, W.: Zentralen Orte in Süddendeutschland. Iena, Fischer, 1933.

Curry, L.: The random spatial economy: an exploration in settlement theory. Annals of the Association of American Geographers, 138-146 (1964).

De Vries, J.: European Urbanization, 1500-1800. London and Cambridge, (Mass.) 1984.

Fletcher, R.: Settlement archaeology: world-wide comparisons, World Archaeology 18(1) 59-83 (1986).

Gibrat, R.: Les inégalités économiques. Paris, Sirey, 1931.
Guérin-Pace, F.: Deux siècles de croissance urbaine. Paris, Anthropos, 1993.

Haran, E.G.P.; Vining, D.R.: On the implications of a stationary urban population for the size distribution of cities. Geographical Analysis 5(4), 296-308 (1973).

Janelle, D.G.: Spatial reorganization: a model and concept. Annals of the Association of American Geographers, 348-368 (1969).

Juillard, E.: L'armature urbaine de la France préindustrielle. Bulletin de la Faculté des Lettres de Strasbourg 6, (1970).

Mackinder, H.J.: The physical basis of political geography. Scottisch Geographical Magazine VI, 78-84 (1890).

Madden: On some indications of stability in the growth of cities in the United States. Economic Development and Cultural change 4, 236-252 (1955).

Malecki, E.J.: Growth and change in the analysis of rank-size distributions: empirical findings. Environment and Planning 12, 41-52 (1980).

Moore, F.T.: A note on city size distributions. Economic Development and Cultural Change vol. 7(1), 17-37 (1958).

Moriconi-Ebrard, F.: L'urbanisation du monde. Paris, Anthropos, coll. Villes, 1993.

Moriconi-Ebrard, F.: Geopolis, pour comparer les villes du monde. Paris, Anthropos, coll. Villes, 1994.

Morrill, R.: Migration and the Spread and Growth of Urban Settlement. Lund Studies in Geography, serie B, n²6, 1965.

Parr, J.B.: Models of city size in an urban system. Papers and Proceedings of the Regional Science Association 25, 221-253 (1970).

Parr, J.B.: A note of the size distribution of cities over time. Journal of Regional Economics vol.18, 99-212 (1985).

Parr, J.B.; Reiner, T.A.: A note on the dimensions of a national urban settlement system. Urban Studies 2, 223-230 (1980).

Pumain, D.: La dynamique des villes. Paris, Economica 231 p. 1982.

Pumain, D.; Robic, M.C.: Théoriser la ville. In: Derycke P.H.; Huriot J.M.; Pumain D. (eds.), Penser la ville, pp. 107-161. Paris: Anthropos 1996.

Pumain, D.: Pour une théorie évolutive des villes, L’Espace Géographique 2, 119-134 (1997).

Quandt, R.E.: Statistical discrimination among alternate hypothesis and some economic regularities. Journal of Regional Science 5(2), 1-23 (1964).

Reclus, E.: The evolution of cities. The Contemporary Review 67 (2), 246-264 (1895).

Robson, B.: 1973, Urban Growth, an approach. London, Methuen.

Rosen, K.T.; Resnick, M.: The size distribution of cities: an examination of Pareto Law and Primacy. Journal or Urban Economics 8, 165-186 (1980).

Sheppard, E.: City size distribution and spatial economic change. International Regional Science Review, vol. 7, 127-151 (1982).

Simon, H.: On a class of skew distributions. Biometrika, 42, 425-440 (1955).

Steindl, J.: Random processes and the growth of firms. New York: Hofnur 1965

Suarez-Villa, L.: Metropolitan Evolution, Sectoral Economic Change, and the City-Size Distribution. Urban Studies 25(1), 120 (1988).

Zipf, G.K.: Human behaviour and the principle of least effort. Cambridge (Mass.), Addison Wesley 1949. 